\title{
Linking supply chain configuration to supply chain performance: A discrete event simulation model
}

\author{
Roberto Cigolini ${ }^{a}$, Margherita Pero ${ }^{\mathrm{a}, *}$, Tommaso Rossi $^{\mathrm{b}}$, Andrea Sianesi $^{\mathrm{a}}$ \\ ${ }^{a}$ Department of Management, Economics and Industrial Engineering (DIG), Politecnico di Milano, Italy \\ ${ }^{\mathrm{b}}$ Institute of Technology, Carlo Cattaneo University - LIUC, Italy
}

\section{Received 29 May 2012}

Received in revised form 24 July 2013

Accepted 2 August 2013

Available online 6 September 2013

\section{Introduction}

Supply Chain (SC) performance is one of the fields of research that have attracted the attention of both academicians and industrial practitioners in the recent years. SC performance is tightly linked to SC configuration and to SC management [13,44,25] (Lee et al., [26]) [5,41]. SC configuration tackles decisions concerning the topological structure of the SC: Persson and Olhager [38] include in SC configuration all the decisions concerning the definition of the structure of the SC, therefore SC configuration does not include planning and control related decisions.

SC management concerns the policies to manage materials and information across the entire supply network [36] at the strategic, operational and tactical level (e.g. lot sizing, forecasting methods, see [9]). Indeed, SC management is focused on what to do once a SC has been designed and configured, to achieve cost-related and service-related objectives [42]. SC performance is strongly affected by SC management, particularly with reference to strategy definition [12,35], inventory planning (Ganeshan et al., [14]), customers-suppliers relationship [40], business process connection (Krajewski et al., 2005), internal integration [23] and order policy [28].

While the impacts of SC management policies on SC performance have been extensively investigated (e.g. [12,42,14]; $[40,24] ;[23,6,28])$, the literature devoted to study the link between SC configuration and SC performance is almost sparse

* Corresponding author. Address: Department of Management, Economics and Industrial Engineering (DIG), Politecnico di Milano, Piazza Leonardo Da Vinci, 32, I-20133 Milano, Italy. Tel.: +39 022399 2819; fax: +39 0223994083.

E-mail address: margherita.pero@polimi.it (M. Pero). 
and even not-existent [41]. Therefore, this paper investigates the effects of SC configuration on SC performance. Since a SC without a material management policy cannot be effectively run, the relationships between configuration-related and management-related parameters have been studied under different material management policy, i.e. Economic Order Quantity (EOQ)-based and forecast-based policy. Under a forecast-based policy, the actors of a given SC place their purchasing (or production) orders on the basis of the forecasted demand, while under an EOQ-based policy, the process of purchasing (or production) is triggered by the inventory level, in that when the inventory level drops below a given threshold (usually called Re-Order Point, ROP), an appropriate amount is ordered from either the upstream SC layer or the production system.

Discrete event simulation has been used as a methodological tool. Indeed, given a set of independent variables, which are expected to impact on a set of dependent variables, simulation appears as the most effective tool to outline the actual relationships when the environment is plagued by variance. Variance in SCs is represented by e.g. time dynamics and uncertainty (e.g. [33]): in such contexts, the models based on Linear Programming (LP) algorithms are proved to be weak $[43,9]$ By contrast, the ability of simulation to support "what-if" analyses and to quantify benefits and issues is well known [46] and, for these reasons, simulation is successfully used in business processes re-engineering projects [32].

The paper is structured as follows: Section 2 presents the literature review. Section 3 introduces the model, while Section 4 highlights the experimental campaign. Finally, in Section 5 the main results are discussed and Section 6 reports some concluding remarks and suggestions for future research.

\section{Background}

SC performance can be classified into efficiency and/or effectiveness (Tan et al., [45]) [2] (Holmberg, [19]) [29]. Effectiveness refers to the ability of a firm to fulfil customers' requirements, while efficiency refers to the ability (of a firm) to maximize the use of internal resources, being the output the same. Efficiency is therefore traditionally related to costs, inventory levels, machine utilization and resources productivity, while effectiveness is measured in terms of stock-out (or backlog) occurrence (probability) and stock-out quantities [50]. Both efficiency and effectiveness are important: Beamon [2] stated that, when defining a SC performance measurement system, the main trade-off between costs and service level should never be neglected. The determinants of SC performance (efficiency and effectiveness) can be found both in the realm of SC management - e.g. lot-sizing policies, forecast errors - and of SC configuration [25] (Lee et al., [26]) [5,44].

Studies about SC configuration can be classified in three major areas (Shapiro, 2001): (i) SC composition, which means the identification of entities (firms, etc.) that should join the (constituent) logistic network; (ii) network structure, related to the number of stages, the sourcing strategies (e.g. multiple vs. single) of each entity and nodes' capacity and location [42]; (iii) collaboration level among the nodes [18]. Certain authors (Jagdev and Thoben, [21]) [31] consider collaboration a SC configuration decision, while others (e.g. [42,17]) believe that collaboration results from decisions taken at SC configuration stage, i.e. once the network structure is assessed: according to this viewpoint, collaboration is part of the SC management area.

SC performance is strongly affected by SC configuration: Simchi-Levi et al. [42] stated that nodes' capacity and location are determinant factors of the performance of a SC, but they did not formalize their assumptions, so they did not demonstrate its validity. Helbing and Lammer [17] proposed a model focused on the dynamical property and linear stability of SCs in dependence of the network topology, which is given by the number of stages of the SC and by the sourcing strategy of each node. They demonstrate that the topology of the logistic network has a direct influence on either damped or overdamped system's oscillations. However, their study neither links the dynamical behaviour of the network with SC performance nor it considers other SC configuration elements than the number of stages and the sourcing strategies of each node. Later, Sezen [41] demonstrated that SC configuration significantly impacts resources and output performance: SC configuration is measured in terms of (i) proximity to suppliers, (ii) number of suppliers, (iii) capacity planning along the chain and (iv) coordination of the logistic flow.

On the whole, despite the proven importance of SC configuration in determining SC performance, little work has been done to investigate the relationships between SC configuration decisions and SC performance [3]: Beamon [1] outlined that few scholars study how the number of stages and the definition of which plant of the network will serve which customer affect SC performance, and none of those scholars studies both variables jointly.

\section{Research framework}

This paper aims to investigate how SC configuration affects SC performance under different materials management policies. The research framework is presented in Fig. 1. The independent variables are the SC configuration decisions. In line with Lambert et al. [22], Simchi-Levi et al. [42] and Pero et al. [36], SC configuration is described by the following parameters:

i. the number of sources each node buys from; this parameter is called "multiple sourcing" and - from a managementrelated perspective - it leads to decide whether adopting a multiple or a single sourcing strategy;

ii. the amount of inventory capacity available at each node and the number of nodes at each level; this parameter is called "splitting";

iii. the distance between nodes; this parameter is called "distance" and it represents the location of SC nodes or the SC footprints; 


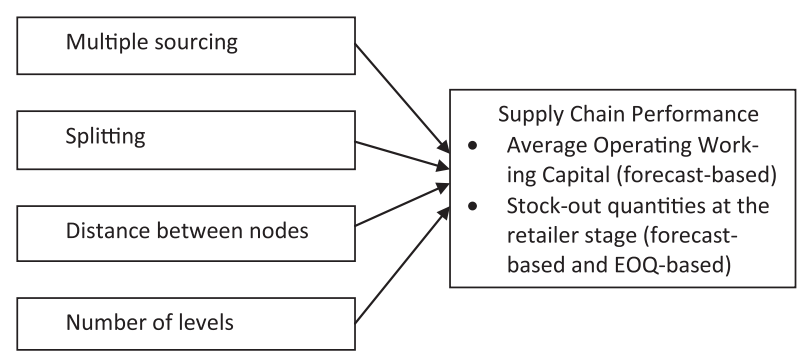

Fig. 1. The model framework.

iv. the number of levels, i.e. the number of echelons of the SC; e.g. a two-stage SC is composed by n retailers and m manufacturers.

Although many SC performance indexes could be measured (e.g. transportation costs, quality, flexibility, etc.) in line with the research of Forrester [13] and Sterman [44], the independent variables of the model are: (i) the average inventory level and (ii) the number of stock-outs. Besides, this study aims to investigate the impact of SC design decisions on SC performance, whilst investigating the strength of such relations goes beyond the scope of the research.

The relations between independent variables and performance indexes are studied under different material management policies. Two material management policies have been studied here: forecast-based and EOQ-based policy. Under the forecast-based management policy, SCs actors define the quantity to order upstream (or to manufacture directly) on the basis of forecasted demand, while under the EOQ-based management policy, purchasing or production is triggered by stock level: whenever the inventory level drops below a given threshold, a certain quantity is ordered either to the upstream SC stage or to the production system. Depending on the material management policy, the performance to monitor varies: under EOQbased policy there is no need to monitor average inventory level, since the stock level is defined by the EOQ itself and by the Re-Order Point (ROP).

\section{Methodology}

To investigate the above mentioned relationships, two simulation models have been developed respectively for the forecast-based and for the EOQ-based context, by means of ARENA ${ }^{\mathrm{TM}}$ software tool. To validate both models, the step function and the run control function provided by ARENA ${ }^{\mathrm{TM}}$ have been employed.

Indeed, simulation has been proposed for SC configuration purposes, e.g. to optimize the portfolio of suppliers under uncertainty [11], to effectively design SCs operations [49], to assess the benefits of integrating business processes at different tiers of the SC [47], to develop dynamic tools for studying SCs [37], to support managers in designing and redesigning SCs $[27,7]$ and to assess risks and benefits of implementing e-procurement [48]. In all the papers above, simulation allowed for measuring the impact of several SC configuration decisions on SC performance.

The same is true with reference to the use of simulation to assess the impact of SC management decisions on SC performance. Daniel and Rajendran [10] demonstrated that simulation optimizes the performance of a single-product serial SC operating with a base-stock policy. Cigolini and Rossi [8] developed a methodology to improve the use of production facilities. Pirard et al. [39] applied to a real-life problem a simulation model focused on activities which take place in and between production and distribution centres, and these authors provided an in-depth evaluation of the effectiveness of different policies.

To perform the simulation study, the SMDP (Simulation Model Development Process) approach by Manuj et al. [30] has been followed. Fig. 2 depicts the activities performed in each step and the required details.

\subsection{Assumptions and limitations}

The analyzed SCs belong to the Fast Moving Consumer Goods (FMCG) industry. Each SC is composed of retailer(s), distributor(s) and manufacturer(s) that - respectively - sell(s), distribute(s) and produce(s) a range of homogenous products that can be considered as if they were a single product, e.g. chocolate and pasta. Each node of the SC places orders to the upstream layer (without direct deliveries from manufacturer to retailer), on the basis of either the EOQ-ROP model or forecasted demand (through an exponential smoothing model). Due to the need to properly study the impact of SC configuration on SC performance, no collaborative practices (e.g. Vendor Managed Inventory - VMI and Collaborative Planning Forecasting and Replenishment - CPFR) are considered, even though both they are commonplace in many industries (see e.g. Gutgeld and Beyer, [16] and [4]) and they are recognized to have a direct impact on SC performance [51].

End customer demand is modelled as follows: the inter-arrival time of end customers is drawn from an exponential distribution and the quantity requested by each customer is drawn from a normal distribution. At the retailer stage, a stock out occurs whenever a product is not available (as stock on hand) when a customer order arrives: stock-out is modelled merely 
Step 1: Formulate problem

State model objective precisely (see section 3 )

$\downarrow$

Step 2: Specify independent and dependent variables

Define independent variables (see section 3)

Define dependent variables (see section 3)

Step 3: Develop and validate conceptual model

Specify assumptions, algorithms, and model components (see sections 4.1, 4.2, and 4.3)

Step 4: Collect data

Define data requirements (see section 4.4)

$\downarrow$

Step 5: Develop and verify computer-based model

Develop a detailed flowchart (see Pero et al. 2010, and Pero et al. 2008)

Choose programming environment (see section 4)

Step 6: Validate the model

Perform a structured walk-through (see section 4)

Check for reasonableness of results (see sections 5 , and 6)

Perform sensitivity analysis (see table 1)

$\downarrow$

Step 7: Perform simulations

Specify sample size (see section 4.4)

Specify run length and warm-up period (see section 4.4)

Perform simulation runs (see section 4.4)

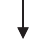

Step 8: Analyze and document results

Establish appropriate statistical techniques (see section 5)

Document results (see section 5 )

Fig. 2. The simulation approach.

as an over-the-counter lack of materials and SC is supposed to be neither robust nor resilient [52]. However, when an order arrives at another actor (except from a retailer), and stock on hand does not allow to fulfil the order, a backlog order is generated and it is fulfilled as soon as the corresponding product is available.

All the distributors aim at maximizing capacity utilization: if the available capacity at a given layer is lower than the capacity at the upstream layer, upstream nodes sell products also to actors (nodes) outside the considered SC. This is in line with the tendency of logistics service providers and distributors to maximize warehouse utilization rate, given the huge opportunity cost of leaving empty space in a warehouse. This is not true for manufacturers, that have over-capacity, to guarantee adequate flexibility (e.g. [34]).

\subsection{Simulation model in forecast-based contexts}

The retailer, at the end of each period (e.g. $t-1$ ), forecasts the expected demand for the next period $(t)$, compares the inventory level (including safety stocks) to the expected demand and places an order $\left(O_{t}\right)$, to the upstream layer. When the retailer receives an order, it comes from customer demand and it is fulfilled with stock on hand. Every time retailer's inventory is not sufficient to fulfil (final) customer demand, the retailer experiences a stock-out. The distributor and the manufacturer, at the end of each period (e.g. $t-1$ ) fulfil the demand coming from downstream layer - i.e. retailer(s) through stock on hand: if inventory level is not sufficient, they calculate the backlog, forecast the expected demand for the next period $(t)$, compare the inventory level with the expected demand and place an order $\left(O_{t}\right)$, to the upstream layer.

An order placed at the end of period $t$ is received downstream at time $t+d / s$ (provided that supplier's stock on hand inventory is sufficient), where $d$ is the distance between supplier and customer and $s$ is the average speed of the transport means. If the order cannot be filled out, a partial consignee occurs and the supplier backlog level increases accordingly. Manufacturers have limited production capacity whereas each actor has unlimited storage capacity and both manufacturers and distributors have unlimited transport capacity. Finally, the end customer demand (at the retailer stage) is represented through the final customers inter-arrival time (drawn from an exponential distribution) and through the quantity bought by each customer (drawn from a normal distribution).

Expected demand $\left(E D_{t}\right)$ is taken from a recurrent exponential smoothing involving actual demand of the previous period $\left(A D_{t-1}\right)$ : 


$$
E D_{t}=\alpha \cdot A D_{t-1}+(1-\alpha) \cdot E D_{t-1}
$$

where $\alpha$ (which ranges from 0 to 1 ) is the importance given to the actual demand when compared to the expected demand (in the model $\alpha=0.5$ ). For the retailer, $t$ is the sum of time fence between two consecutive orders to the distributor (in the model 1 week) and of the transportation lead time from the distributor (in the model $d / s$, i.e. the rate between the distance and the speed of the transportation means). For the distributor and the manufacturer $t$ is the time interval between two orders (in the model 1 week).

The order $O_{t}$ is expressed by:

$$
O_{t}=\max \left(0 ; O_{t}^{*}\right)
$$

where, for the retailer:

$$
O_{t}^{*}=E D_{t}-I N V_{t-1}
$$

being $I N V_{t-1}$ the inventory on hand of the actor at the end of period $t-1$ (i.e. at the beginning of period $t$ ). For the distributor and the manufacturer, that experience backlogs instead of stock-outs:

$$
O_{t}^{*}=E D_{t}-I N V_{t-1}+B_{t-1}
$$

where $B_{t-1}$ is the backlog generated during the period $t-1$. In turn:

$$
B_{t-1}=\max \left(0 ; A D_{t-1}-I N V_{t-2}\right) .
$$

For each period, retailer's actual demand is calculated as the sum of the final customers' demands arrived during the same period and properly fulfilled (the retailer does not record stock-outs since the analyzed SCs belong to the FMCG industry, see Section 4.1). Distributor's and manufacturer's actual demand (for each period) are given by orders placed in the same period by the downstream stage. The quantity provided to the retailer and to the distributor in the same period by the distributor and the manufacturer respectively are:

$$
Q_{t}=\min \left(I N V_{t-1} ; A D_{t}\right) \text {. }
$$

Notice that - after $d / s$ time units $-Q_{t}$ is added to the customer's inventory and if supplier's inventory is unable to fulfil the customer's order, the supplier has to provide the customer as soon as possible with the pending quantity $\left(P Q_{t}\right)$, where:

$$
P Q_{t}=A D_{t}-I N V_{t-1} \text {. }
$$

\subsection{Simulation model in EOQ-based contexts}

Within the studied SCs, a given actor $k$ continuously checks the value of its inventory, given - at time $t-$ by $I N V_{k, t}$ :

$$
I N V_{k, t}=I N V_{k, t-1}-Q_{k, t}+Q_{k+1, t-d / s}
$$

where $I N V_{k, t-1}$ is the inventory of actor $k$ at time $t-1, Q_{k, t}$ is the quantity that actor $k$ will deliver, after the transportation lead time, to the downstream actor $k-1$ (due to the order placed to $k$ by $k-1$ at time $t$ ) and $Q_{k+1, t-d / s}$ is the quantity delivered at time $t$ to the actor $k$ by the upstream actor $k+1$ (due to the order placed to $k+1$ by $k$ at time $t-d / s$ ). Inventory includes also safety stocks.

The quantity provided by actor $k$ to the downstream actor at time $t$ is given by:

$$
Q_{k, t}=\min \left(I N V_{k, t-1} ; O_{k-1, t}\right),
$$

i.e. it is the minimum between the inventory on hand and the order received by the downstream actor. Finally, such an order is equal to the economic order quantity of the actor if its inventory is lower than the reorder point level, or it is equal to 0 if the above mentioned condition is not verified, i.e.:

$$
O_{k, t}=\left\{\begin{array}{ll}
E O Q_{k} & I N V_{k, t} \leqslant R O P_{k} \\
0 & \text { Otherwise }
\end{array},\right.
$$

An order placed at time $t$ by actor $k$ to actor $k+1$ is received downstream at time $t+d / s$ (provided that $k+1$ 's stock on hand is sufficient), where $d$ is the distance between $k+1$ and $k$ and $s$ is the average speed of the transport means. If the order cannot be filled out, a partial consignee occurs and the $k+1$ backlog level increases accordingly. In this case actor $k+1$ has to provide the downstream actor as soon as possible with the pending quantity $\left(P Q_{t}\right)$, where:

$$
P Q_{k, t}=O_{k-1, t}-I N V_{k, t-1} \text {. }
$$

As under the forecast-based context, manufacturer has limited production capacity whereas each actor has unlimited storage capacity and the manufacturer and the distributor have unlimited transport capacity. End customer demand (at the retailer stage) is represented through the final customers inter-arrival time (drawn from an exponential distribution) and the quantity bought by each customer (drawn from a normal distribution). When the retailer is unable to fulfil the final customer demand, a stock out occurs. 


\subsection{Design of experiments}

To investigate the relationship between SC configuration and SC performance, both under forecast-based contexts and EOQ-based ones, five scenarios have been simulated. The first scenario is the base case one (BC) represented by a SC composed of one retailer, one distributor and one manufacturer. The other four scenarios come from the BC one by changing one SC configuration parameter. The design parameters taken into account here are the ones outlined by Simchi-Levi et al. [42]. In particular, scenario 2 (called Distance - DIS), differs from BC because the distance between manufacturer and distributor

Scenario
Scenario 1
Base Case
(BC)

Fig. 3. Overview of the modelled scenarios.

Table 1

Overview of the experimental campaign.

\begin{tabular}{|c|c|c|c|c|c|c|c|}
\hline \multirow{2}{*}{$\begin{array}{l}\text { Scenario } \\
\text { Unit of } \\
\text { measure }\end{array}$} & \multirow[t]{2}{*}{ Acronym } & \multicolumn{3}{|c|}{ Topological parameters } & \multicolumn{3}{|c|}{ Demand and production rates } \\
\hline & & $\begin{array}{l}d_{M D}(\text { if } \\
\text { applicable }) \\
(\mathrm{km})\end{array}$ & $\begin{array}{l}d_{D R} \text { (if } \\
\text { applicable) } \\
(\mathrm{km})\end{array}$ & $\begin{array}{l}\text { Others (if } \\
\text { applicable) }\end{array}$ & $\begin{array}{l}\text { End customers arrivals at } \\
\text { the retailer(s) } \\
\text { (h) }\end{array}$ & $\begin{array}{l}\text { Pieces bought per } \\
\text { end customer } \\
\text { (pieces) }\end{array}$ & $\begin{array}{l}\text { Manufacturer's } \\
\text { production rate } \\
\text { (pieces/h) }\end{array}$ \\
\hline Base Case & $\mathrm{BC}$ & 25 & 400 & $\begin{array}{l}\text { Not } \\
\text { applicable }\end{array}$ & $\operatorname{Exp}(1)$ & $\operatorname{Norm}(4,1)$ & 175 \\
\hline Distance & $\begin{array}{l}\text { DIS1 } \\
\text { DIS2 } \\
\text { DIS3 } \\
\text { DIS4 }\end{array}$ & $\begin{array}{l}212.5 \\
400 \\
30 \\
37.5\end{array}$ & $\begin{array}{l}212.5 \\
25 \\
480 \\
600\end{array}$ & $\begin{array}{l}\text { Not } \\
\text { applicable }\end{array}$ & $\operatorname{Exp}(1)$ & $\operatorname{Norm}(4,1)$ & 175 \\
\hline $\begin{array}{c}\text { Number of } \\
\text { sources }\end{array}$ & $\begin{array}{l}\text { NSO1 } \\
\text { NSO2 } \\
\text { NSO3 } \\
\text { NSO4 } \\
\text { NSO5 }\end{array}$ & 25 & 400 & $\begin{array}{l}2 \text { sources } \\
3 \text { sources } \\
4 \text { sources } \\
5 \text { sources } \\
8 \text { sources }\end{array}$ & $\operatorname{Exp}(1)$ & $\operatorname{Norm}(4,1)$ & $175 \times \mathbf{N}_{\text {sources }}$ \\
\hline $\begin{array}{l}\text { Number of } \\
\text { stages }\end{array}$ & $\begin{array}{l}\text { NST1 } \\
\text { NST2 } \\
\text { NST3 }\end{array}$ & 25 & 400 & $\begin{array}{l}4 \text { stages } \\
5 \text { stages } \\
6 \text { stages }\end{array}$ & $\operatorname{Exp}(1)$ & $\operatorname{Norm}(4,1)$ & 175 \\
\hline Splitting & $\begin{array}{l}\text { SPL1 } \\
\text { SPL2 } \\
\text { SPL3 } \\
\text { SPL4 }\end{array}$ & 25 & 400 & $\begin{array}{l}a=50 \% \\
a=33 \% \\
a=25 \% \\
a=20 \%\end{array}$ & $\operatorname{Exp}(1 / a)$ & $\operatorname{Norm}(4,1)$ & 175 \\
\hline
\end{tabular}


as well as the one between distributor and retailer are differently distributed than under BC. Scenario 3 (called Number of SOurces - NSO) differs from BC because there are two (or more) retailers and two (or more) distributors. Scenario 4 (called Number of STages - NST) differs from BC because there are four (or more) stages, i.e. one (or more) wholesalers are added in between the retailer and the distributor. Scenario 5 (called Splitting - SPL) differs from BC because the capacity of either retailer is differently distributed than under BC.

Fig. 3 provides an overview of the scenarios, while Table 1 provides the main parameters useful to describe each scenario.

Referring to NOS and SPL, only the retailer stage is subject to change: under NOS, the number of retailers equals the one of distributors just to make the capacity at a given stage consistent with the capacity at the other stages, so that different distributors have the same probability to receive orders by each retailer. The length of each time bucket is 1 week. End customers inter-arrival time is exponentially distributed with mean equal to $1 \mathrm{~h}$. The number of pieces bought per end-customer is normally distributed with mean and standard deviation of 4 and 1 pieces respectively. Parameter $\alpha$ of the exponential smoothing is the same for each node and equals to 0.5. Initial inventory of each node accounts for 2000 pieces and the expected demand of each actor for the first period is 0 . The average speed of the transport means is $60 \mathrm{~km} / \mathrm{h}$. Simulation run length is 21 years: the first one is used to warm-up the model and thus disregarded.

Statistics are collected (for each run and for each simulated day) about stock-outs (number of pieces) at the retailers and stock-outs and backlogs (number of pieces) at all the other actors, as well as inventory levels (number of pieces) of all the actors. In particular, stock-outs used for the analyses are the cumulative value over a simulated year, thus 20 stock-outs per run are available. Backlogs and inventory level used in the analyses are the average values per actor over one simulated year.

\section{Results}

The relationship between SC configuration and SC performance has been investigated by means of ANOVA and linear regression on the data gathered via simulation (see Tables 2 and 3). The effect on performance of each decision variable has been studied independently in each context (i.e. forecast-based and EOQ-based context). For each scenario, the results

Table 2

Effects of SC configuration on effectiveness-related performance.

\begin{tabular}{|c|c|c|c|}
\hline \multirow[t]{2}{*}{ Variable } & \multirow[t]{2}{*}{ Relation } & \multicolumn{2}{|l|}{ Context } \\
\hline & & Forecast-based SC & EOQ-based SC \\
\hline \multirow{2}{*}{$\begin{array}{l}\text { Distance } \\
\text { between } \\
\text { nodes }\end{array}$} & $\begin{array}{l}\text { Distributor nearer to the retailer and farther away from the } \\
\text { manufacturer - Stock outs at retailer }\end{array}$ & + ANOVA $p$-value $=0$ & Not available \\
\hline & Length of the SC - Stock outs at retailer & $\begin{array}{l}0 / \text { tendency to }+ \text { ANOVA } p \text { - } \\
\text { value }=0.882\end{array}$ & 0 ANOVA $p$-value $=0.929$ \\
\hline \multirow[t]{3}{*}{$\begin{array}{l}\text { Multiple } \\
\text { sourcing }\end{array}$} & Multiple sourcing - Stock outs at retailer & - ANOVA $p$-value $=0$ & $\begin{array}{l}0 / \text { tendency to +ANOVA } p \text { - } \\
\text { value }=0.51\end{array}$ \\
\hline & Backlog at distributor stage - Stock outs at retailer & + ANOVA $p$-value $=0$ & Not available \\
\hline & Backlog at manufacturer - Stock outs at retailer & + ANOVA $p$-value $=0$ & Not available \\
\hline Number of levels & Number of levels - Stock-outs at retailer & - ANOVA $p$-value $=0$ & 0 ANOVA $p$-value $=0.995$ \\
\hline \multirow[t]{3}{*}{ Splitting } & Number of levels - Backlog at distributors & Not available & Not available \\
\hline & Number of levels - Backlog at manufacturer & Not available & Not available \\
\hline & Splitting - Stock-outs at retailer stage & + ANOVA $p$-value $=0$ & + ANOVA $p$-value $=0$ \\
\hline
\end{tabular}

Table 3

Effects of SC configuration on efficiency-related performance.

\begin{tabular}{|c|c|c|c|}
\hline \multirow[t]{2}{*}{ Variable } & \multirow[t]{2}{*}{ Relation } & \multicolumn{2}{|l|}{ Context } \\
\hline & & Forecast-based SC & EOQ-based SC \\
\hline \multirow[t]{2}{*}{$\begin{array}{l}\text { Distance between } \\
\text { nodes }\end{array}$} & $\begin{array}{l}\text { Distributor near to the retailer and far away from the manufacturer - } \\
\text { Stock per actor }\end{array}$ & - ANOVA $p$-value $=0$ & Not available \\
\hline & Length of the SC - Stock per actor & + ANOVA $p$-value $=0.013$ & + ANOVA $p$-value $=0$ \\
\hline \multirow[t]{3}{*}{ Multiple sourcing } & Multiple sourcing - Stock at retailer & $\begin{array}{l}0 / \text { tendency to }- \text { ANOVA } p \text { - } \\
\text { value }=0\end{array}$ & + ANOVA $p$-value $=0$ \\
\hline & Multiple sourcing - Stock at distributor & + ANOVA $p$-value $=0$ & Not available \\
\hline & Multiple sourcing - Stock at manufacturer & + ANOVA $p$-value $=0$ & Not available \\
\hline Number of levels & Number of levels - Average stock in chain & + ANOVA $p$-value $=0$ & $\begin{array}{l}0 \text { ANOVA } p- \\
\text { value }=0.868\end{array}$ \\
\hline \multirow[t]{2}{*}{ Splitting } & Splitting - Stock at retailer & + ANOVA $p$-value $=0$ & $\begin{array}{l}- \text { ANOVA } p- \\
\text { value }=0\end{array}$ \\
\hline & Splitting - Average stock in chain & 0 ANOVA $p$-value $=0.964$ & Not available \\
\hline
\end{tabular}


of each configuration have been compared to the Base Case (BC) of the corresponding context. In this way, we could check whether there is statistical evidence that SC performance is affected by SC configuration, and - if so - we could outline the direction of the effect, i.e. increase or decrease. Moreover, to explain the above outlined relations, intermediate variables values have been recorded and analyzed too: for this reason, some variables have been analyzed only in either context.

In Tables 2 and 3, a positive relation, between the variable and the performance presented in the column "relation", was indicated with a "+" in the column "context". For instance a positive relation exists between Backlog at distributor stage and Stock outs at retailer, i.e. when the Backlog at distributor stage increases the Stock outs at retailer increases as well. Vice versa, a minus indicates that a negative relation exists between the variable and the performance.

\subsection{Forecast-based contexts}

As far as DIS scenario is concerned, two main phenomena have been investigated: (i) the impact of the distributor's location with respect to the retailer (see e.g. DIS1 vs. DIS2) and (ii) the impact of the length of the supply chain on performance (see e.g. DIS1 vs. DIS3).

ANOVA results show that the distance of the distributor from both the manufacturer and the retailer affects supply chain performance ( $p$-value $=0$ ). The analysis of average stock outs and average stock per actor under BC, DIS1 and DIS2 outlines that the shorter the distance between distributor and retailer, the higher the stock-outs at the retailer stage and the lower the average stock per actor.

This is due to that, on the one hand, retailer's order size depends on the transportation lead time between retailer and distributor, and so on the distance between them. On the other hand, due to the lack of information sharing between retailer and distributor, retailer places its orders based on expected demand, which actually is the quantity requested by customers during the lead time, thus reducing stock and increasing stock-out occurrence. In fact, when the distributor is close to the retailer and far from the manufacturer, the retailer places small orders. However, when orders cannot be fulfilled by the distributor, the retailer has to wait a long time to get the products during this period, and the retailer has a higher probability to experience stock outs. This effect is expected to be mitigated e.g. by sharing demand forecast and/or stock levels, between retailer and distributor.

Under forecast-based context, as expected, the length of the SC has been proved to affect the average stock per actor ( $p$-value $=0.013$; residuals normally distributed): again, the higher the distance between nodes, the bigger the orders placed by the nodes, thus the higher the stocks levels. Finally, stock outs are not affected by the length $(p$-value $=0.882)$. Despite this, a slight increase has been recorded.

Under NSO scenario, all the analyzed performance indexes (i.e. stock-out at retailer, backlog at distributor, stock at distributor and stock at the retailer) vary depending on the SC configuration. When the number of sources increases, stocks and backlogs at both distributor and manufacturer increase, while stock-out at each retailer is stable, with a slight tendency to decrease. The increase of stocks at distributor coupled with an increasing number of backlogs at distributor confirms the bullwhip effect, early recognized by Forrester [13]. This result suggests that topology can be a cause of such an effect. The reason of the outcomes above lies in the increase of demand variance perceived by distributors due to the increased number of retailers. Since the orders received by each distributor are taken from a binomial statistical distribution, when the number of retailers increases, the demand variance experienced by each distributor (i.e. orders placed to a given distributor by retailers) increases as well (Greene, [15]). High demand variance leads to high forecasting errors, which badly affects SC performance. When demand is higher than forecasted, retailers' demand cannot be fulfilled via stock on hand, thus increasing the likelihood of stock-outs at the retailer. When demand is lower than forecasted, demand for the current period is fulfilled and stock at the distributor increases. This reduces the probability of under-fulfilment of retailers demand in the following periods. To summarize, an increase of the number of sources results in enhancing SC performance only for the retailer, at the expenses of distributor(s) and manufacturer(s), with an overall increase of stocks. This may lead to hurdles for the retailer to collaborate with other actors of the SC.

Under NST scenario, an increased number of levels - given the same overall distance between manufacturer and retailer - results in higher stocks along the SC and less stock outs at the retailer. No reduction of the backlogs at other layers has been registered: this might be due to that backlogs are null also under $\mathrm{BC}$, as a consequence of the parameters setting in the simulation model.

Under SPL scenario, a different capacity distribution of either retailer affects stock-outs and the average inventory level at the retailer stage ( $p$-value $=0$; residuals normally distributed), whereas it does not impact the average stock along the SC $(p$-value $=0.964)$. From a managerial perspective, these results suggest that - being the final customers' demand the same - a greater number of retailers reduces the SC effectiveness (i.e. stock-outs increase), whilst it shifts the stock downstream. This effect is quite similar to bullwhip effect in that retailers experience higher stock-outs although they have high amount of stock on hand [20]. To this purpose, SPL scenario could be investigated, particularly to verify whether an increased number and a changed size of retailers affect the ratio between out-coming and in-coming orders at the different SC stages.

\subsection{EOQ-based contexts}

As expected, within EOQ-based contexts, the actual lead time - i.e. the replenishment lead time the retailer experiences, determines stock-outs and stock-out quantities, since safety stocks level is computed using actual lead time. In fact, when 


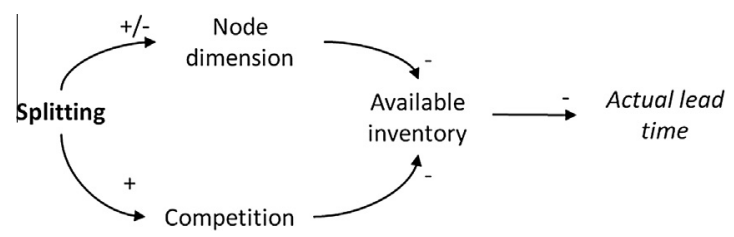

Fig. 4. Relations between 'splitting' and 'actual lead time'.

the actual lead time is higher than expected, safety stock are used to fulfil demand, and, if safety stocks are not enough, the retailer is affected by stock-outs. The stock-out quantity depends on the time the retailer has to wait for replenishment, i.e. on the actual lead time.

Under DIS scenario the location of the distributor (in terms of distance between distributor and manufacturer and distance between distributor and retailer), does not affect stock-outs at retailer stage. This is due to that in calculating both safety stocks and re-order point the increase of lead time and, with reference only to safety stocks, the increase of the lead time standard deviation, are taken into account. As expected, no statistical evidence of an impact on effectiveness performance due distance has been recorded ( $p$-value $=0.929$ ).

Under NSO scenario, there is no statistical evidence that two (or more) retailers and two (or more) distributors affect stock-outs ( $p$-value $=0.510$ ), although a tendency to higher stock-outs when the number of sources increases is recognizable. This can be linked to that the higher the number of distributors the retailer buys from, the lower the times a stock-out occurs (if you compare multiple sourcing vs. number of stock outs you yield a $p$-value $=0.045$ ). Indeed, when the number of retailers increases, both the probability that each retailer places an order to a different distributor and the probability that all the retailers place orders to the same distributor decrease. Retailers can be supposed to experience stock-outs when a certain number of retailers place orders to the same distributor. The threshold number of retailers that triggers stock-outs depends on the parameters setting of the model. However, broadly speaking, the threshold above lowers as the number of retailers increase: the orders received by each distributor is taken from a $B(n ; p)$ - i.e. a binomial distribution - so, given the number of distributor, the probability that $m$ retailers place an order to the same distributor is lower than the probability that $m-1$ retailers do the same (e.g. under a 5-distributor scenario, the probability to receive orders from 3 retailers is lower than the probability to receive orders from 2 of them).

From a managerial viewpoint, the result above suggests that multiple sources leads to reduce the stock-out probability, but once a stock-out has occurred - stock-out quantity is higher. This is very harmful where demand is seasonal (e.g. icecreams, soft drinks): when stock-out occurs during the peak of demand. Finally, multiple sourcing affects stock at the retailer $(p$-value $=0)$ : when there are more sources, stocks at retailer increase accordingly.

Under NST scenario, there is no statistical evidence that one (or more) wholesalers in between the retailer and the distributor has an impact on retailer stocks ( $p$-value $=0.868$ ) and on stock-outs ( $p$-value $=0.995$ ). Despite the increased buffers to prevent from stock outs, there is no improvement with respect to BC probably because there are no stock-outs under BC.

Under SPL scenario, a different capacity distribution of either retailer impacts both stock outs and stocks ( $p$-value $=0$ in either case). When capacity is partitioned among more actors, stock-outs at the retailer stage increase, whereas stocks at the retailer decrease. In this case, the effect on stock-outs can be motivated by the increase of actual lead time between distributor and retailer. ANOVA results show that splitting affects actual lead time ( $p$-value $=0.012$ ) and when many actors are involved, actual lead time increases, even being overall demand and overall capacity the same as under BC. This unexpected effect can be due to the relationships among SC configuration parameters, i.e. 'splitting' and e.g. competition, available inventory, node dimension, etc. Fig. 4 shows these relationships.

Actually, 'splitting' variable represents a twofold decision: on the one hand it answers the question: "how many nodes are activated at a given level?", while - on the other hand - it answers the question: "how much inventory capacity is installed at a given node?". This means that 'splitting', on the one hand, impacts on the 'competition' among nodes of the same stage, which leads to a negative impact on 'available inventory' for each retailer. On the other hand, 'splitting' impacts also on the 'node dimension'. Indeed, when a given node is endowed with more capacity than other nodes, the sign of the relation (involving that node) is plus and vice versa when a given node is endowed with less capacity than others. Moreover since nodes are assumed not to implement any collaborative practice, such as reserved capacity, orders of each node are fulfilled through available stock upstream as soon as each order is placed. Small nodes place smaller orders than big nodes. Therefore the probability to fulfil orders of small nodes is higher than of big nodes, thus small nodes are provided with higher available inventory upstream than big ones. This effect has been expressed in Fig. 3 by the negative arrow from 'node dimension' to 'available inventory'.

\section{Conclusions and future research paths}

This paper contributes to shed light on the role of SC configuration in determining SC performance in EOQ-based and forecast-based contexts. In line with the previous researches by Helbing and Lammer [17], Sezen [41] and Pero et al. [36], it has been investigated how SC efficiency and effectiveness indexes are affected by SC configuration, i.e. number of stages, sourc- 
ing strategies of each node and nodes capacity and location [42]. The analyzed SC configuration parameters (independent variables) are: the number of sources each node buys from (multiple vs. single sourcing), the decision to install a given amount of production/inventory capacity at a given node and to activate a given number of nodes (splitting), the location of the nodes (distance between nodes) and the number of levels of the SC. The analyzed SC performance index are: the inventory level of actors in the SC and stock-outs at the retailer stage.

Through simulation, environments have been set up to model a EOQ-based SC, and a forecast-based SC. A base-case SC has been defined and the SCs which can be obtained from the BC SC by changing one parameter of SC configuration (i.e. an independent variable), have been built. Then, to test different values of independent variables, simulation models have been differently parameterized: this led to various configurations, each of them differing from another one by the value of the SC configuration parameter the scenario refers to. In EOQ-based SCs, each node runs its facility by applying the EOQROP model. For EOQ-based contexts, 7 simulation models have been built. In forecast-based SCs, each node define the quantities to order or to produce on the basis of forecasted demand and available inventory. To represent and study such a context, 17 simulation models have been developed.

Through ANOVA coupled with linear regression - both applied to simulation results - the effect of SC configuration on SC performance has been outlined for both contexts (see Tables 2 and 3). This leads to some meaningful managerial implications.

First of all, whichever the context, long SCs do not affect retailers' service level, but require significant investment in stocks. Given the same distance between the factory and the retailer, by increasing the layers of the distribution network (i.e. by increasing the levels of the SC), the service level is enhanced only in forecast-based contexts and at the expenses of increased stocks.

As far as the number of sources, in forecast-based context, retailers' performance enhances, while distributors' and manufacturers' one deteriorates. Vice versa, in EOQ-based context, retailers' performance tends to worsen in terms of effectiveness, while retailer stocks increase. In both contexts, collaborative practices could be fruitfully put in place to counteract this effect: in forecast-based contexts, information sharing can mitigate the impact of order variability; in EOQ-based context, practices such as reserved capacity can ensure retailers to have available stocks when needed. However, in forecast-based context retailers experience better performance, which can become a hurdle to collaboration. The opposite is true, in EOQ-based context, where retailers have a greater interest in cooperating with suppliers.

Regarding the distribution of capacity of either retailer (i.e. the variable 'splitting'), whichever the context, the ability of the SC to fulfil customers decreases, thus causing high stock-outs at the retailer stage, since capacity is portioned among a greater number of retailers. However, in forecast-based context, retailer stocks increase, while in EOQ-based context the opposite is true. Since the phenomenon experienced by forecast-based contexts seems quite similar to bullwhip effect [13], similar countermeasures might be put in place. However, future research is still needed to investigate to which extent the SC dynamics generated by an increased number of retailers actually resembles to the one outlined by Forrester. In EOQbased contexts, the result presented above supports the practice of fast-moving consumer goods industry, where supermarkets have replaced retailers in the last decades.

Finally, the proposed model undoubtedly presents some limitations: first, SC performance encompasses more than the mere inventory level and stock-outs: further research should be devoted to include more performance indexes into the analysis. Second, the effect on SC performance of the many other available combinations of independent variables should be analyzed. Third, the relationships between SC configuration and SC performance have been analyzed under two materials management policies (i.e. EOQ-based and forecast-based ones), while further research is needed to test different models on these relationships, maybe involving also collaboration and cooperation among actors. Finally, this study should be fruitfully extended to multiple product environments, by also involving real-life case-studies.

\section{References}

[1] B.M. Beamon, Supply chain design and analysis: models and methods, International Journal of Production Economics 55 (3) (1998) $281-294$.

[2] B.M. Beamon, Measuring supply chain performances, International Journal of Operations and Production Management 19 (3) (1999) 275-292.

[3] R. Bhatnagar, A.S. Sohal, Supply chain competitiveness: measuring the impact of location factors, uncertainty and manufacturing practices, Technovation 25 (5) (2005) 443-456.

[4] M. Caridi, R. Cigolini, D. De Marco, Linking autonomous agents to CPFR to improve SCM, Journal of Enterprise Information Management 19 (5) (2006) $465-482$.

[5] F. Chen, Z. Drezner, J.K. Ryan, D. Simchi-Levi, Quantifying the bullwhip effect in a simple supply chain: the impact of forecasting, lead times and information, Management Science 46 (3) (2000) 436-443.

[6] Z. Cheng, Z. Chenghong, Design and simulation of demand information sharing in a supply chain, Simulation Modelling Practice and Theory 15 (1) (2007) 32-46.

[7] R. Cigolini, M. Pero, T. Rossi, An object-oriented simulation meta-model to analyse supply chain performance, International Journal of Production Research 49 (19) (2011) 5917-5941.

[8] R. Cigolini, T. Rossi, A note on supply risk and inventory outsourcing, Production Planning and Control 17 (4) (2006) $424-437$.

[9] S. Chopra, P. Meindl, Supply Chain Management, Strategy, Planning and Operation, Prentice Hall, Upper Saddle River, NJ, 2001.

[10] J.S.R. Daniel, C. Rajendran, Determination of base-stock levels in a serial supply chain: a simulation-based simulated annealing heuristic, International Journal of Logistics Systems and Management 1 (2-3) (2005) 149-186.

[11] H. Ding, L. Benyoucef, X. Xie, A simulation optimization methodology for supplier selection problem, International Journal of Computer Integrated Manufacturing $18(2 / 3)(2005)$ 210-224

[12] M. Fisher, What is the right supply chain for your product?, Harvard Business Review March-April (1997) 105-116.

[13] J.W. Forrester, Industrial Dynamics, Pegasus Communications, Waltham, Massachussets, 1961. 
[14] R. Ganeshan, T. Boone, A.J. Stenger, The impact of inventory and flow planning parameters on supply chain performance: an exploratory study, International Journal of Production Economics 71 (1-3) (2003) 111-118.

[15] W.H. Greene, Econometric Analysis, Prentice Hall - Upper Saddle River, NJ, 2000.

[16] Y. Gutgeld, D. Beyer, Are you going out of fashion, The McKinsey Quarterly 3 (1995) 55-65.

[17] D. Helbing, S. Lammer, Supply and production networks: from the bullwhip effect to business cycles, in: D. Armbruster, A.S. Mikhailov, K. Kaneko (Eds.), Networks of Interacting Machines: Production Organization in Complex Industrial Systems and Biological Cells, World Scientific, Singapore, 2005, pp. 33-66.

[18] R. Hieber, Supply Chain Management-A Collaborative Performance Measurement Approach, VDF Hochshulverlang ag an der ETH, 2002.

[19] S. Holmberg, A systems perspective on supply chain measurements, International Journal of Physical Distribution \& Logistics Management 30 (10) (2000) 847-868.

[20] K.L. Hsieh, Y.K. Chen, C.C. Shen, Bootstrap confidence interval estimates of the bullwhip effect, Simulation Modelling Practice and Theory 15 (8) (2007) 908-917.

[21] H.S. Jagdev, K.-D. Thoben, Anatomy of enterprise collaborations, Production Planning \& Control: The Management of Operations 12 (5) (2001) 437451.

[22] D.M. Lambert, M.C. Cooper, J.D. Pagh, Supply chain management: implementation issues and research opportunities, The International Journal of Logistics Management 9 (2) (1998) 1-19.

[23] C.W. Lee, I.G. Kwon, D. Severance, Relationship between supply chain performance and degree of linkage among supplier, internal integration, and customer, Supply Chain Management: An International Journal 12 (6) (2007) 444-452.

[24] H.L. Lee, Aligning supply chain strategies with product uncertainties, California Management Review 44 (3) (2002) $105-119$.

[25] H.L. Lee, V. Padmanabhan, S.J. Whang, Information distortion in a supply chain: the bullwhip effect, Management Science 43 (4) (1997) $546-558$.

[26] H. Lee, P. Padmanabhan, S. Whang, Information distortion in a supply chain: the bullwhip effect, Management Science 43 (4) (1997) $546-558$.

[27] M. Leng, M. Parlar, Allocation of cost savings in a three-level supply chain with demand information sharing: a cooperative-game approach, Operations Research 57 (1) (2009) 200-213.

[28] C. Li, S. Liu, A stochastic network model for ordering analysis in multi-stage supply chain systems, Simulation Modelling Practice and Theory 22 (2012) $92-108$.

[29] S. Li, B. Ragu-Nathan, T.S. Ragu-Nathan, S.S. Rao, The impact of supply chain management practices on competitive advantage and organizational performance, Omega 34 (2) (2006) 107-124.

[30] I. Manuj, J.T. Mentzer, M.R. Bowers, Improving the rigor of discrete-event simulation in logistics and supply chain research, International Journal of Physical Distribution \& Logistics Management 39 (3) (2009) 172-201.

[31] H.C. Makatsoris, Y.S. Chang, Design of a demand-driven collaborative supply-chain planning and fulfilment system for distributed enterprises, Production Planning and Control 15 (3) (2004) 256-269.

[32] N. Melão, M. Pidd, Use of business process simulation: a survey of practitioners, The Journal of the Operational Research Society 54 (1) (2003) 2-10.

33] S.A. Melnyk, K.C. Tan, D.R. Denzler, L. Fredendall, Evaluating variance control, order review/release and dispatching: a regression analysis, International Journal of Production Research 32 (1994) 1045-1061.

[34] R. Narasimhan, A. Das, An empirical examination of sourcing's role in developing manufacturing flexibilities, International Journal of Production Research 38 (4) (2000) 875-893.

[35] R. Narasimhan, S.W. Kim, K.C. Tan, An empirical investigation of supply chain strategy typologies and relationships to performance, International Journal of Production Research 46 (18) (2008) 5231-5259.

[36] M. Pero, T. Rossi, C. Noè, A. Sianesi, An exploratory study of the relation between supply chain topological features and supply chain performance, International Journal of Production Economics 123 (2) (2010) 266-278.

[37] F. Persson, M. Araldi, The development of a dynamic supply chain analysis tool-Integration of SCOR and discrete event simulation, International Journal of Production Economics 121 (2) (2009) 574-583.

[38] F. Persson, J. Olhager, Performance simulation of supply chain design, International Journal of Production Economics 77 (2002) $231-245$.

[39] F. Pirard, S. Iassinovski, F. Riane, A generic scalable simulation model for strategic supply chain management with emphasis on production activities, International Journal of Computer Integrated Manufacturing 21 (4) (2008) 455-467.

[40] F. Salvador, C. Forza, M. Rungtusanatham, T.Y. Choi, Supply chain interactions and time-related performances: an operations management perspective, International Journal of Operations and Production Management 21 (4) (2001) 461-475.

[41] B. Sezen, Relative effects of design, integration and information sharing on supply chain performance, Supply Chain Management: An International Journal 13 (3) (2008) 233-240.

[42] D. Simchi-Levi, P. Kaminsky, E. Simchi-Levi, Designing and Managing the Supply Chain, McGraw-Hill, Fairfield, Connecticut, 2001.

[43] T. Sridhar, R. Ganeshan, M. Magazine, Quantitative Methods for Supply Chain Management, Kluwer, Boston, Massachusetts, 1999.

[44] J. Sterman, Business Dynamics: Systems Thinking and Modelling for a Complex World, McGraw Hill, Homewood, Illinois, 2000.

[45] K.C. Tan, V.J. Kannan, R.B. Handfield, Supply chain management supplier performance and firm performance, International Journal of Purchasing and Materials Management 34 (3) (1998) 2-9.

[46] S. Terzi, S. Cavalieri, Simulation in the supply chain context: a survey, Computers in Industry 53 (1) (2004) 3-16.

[47] P. Trkman, M. Indihar Stemberger, J. Jaklic, A. Groznik, Process approach to supply chain integration, Supply Chain Management - An International Journal 12 (2) (2007) 116-128.

[48] P. Trkman, K. McCormack, Estimating the benefits and risks of implementing e-procurement, IEEE Transactions on Engineering Management 57 (2) (2010) 338-349.

[49] S. Umeda, F. Zhang, Supply chain simulation: generic models and application examples, Production Planning and Control 17 (2) (2006) $155-166$.

[50] S. Vachon, R.D. Klassen, Environmental management and manufacturing performance: the role of collaboration in the supply chain, International Journal of Production Economics 111 (2) (2008) 299-315.

[51] C. Zhang, C.H. Zhang, Design and simulation of demand information sharing in a supply chain, Simulation Modelling Practice and Theory 15 (1) (2007) $32-46$.

[52] G.A. Zsidisin, G.L. Ragatz, S.A. Melnyk, The dark side of supply chain management, Supply Chain Management Review 9 (2) (2005) $46-52$. 